Preprints of the

Max Planck Institute for

Research on Collective Goods

Bonn 2010/43

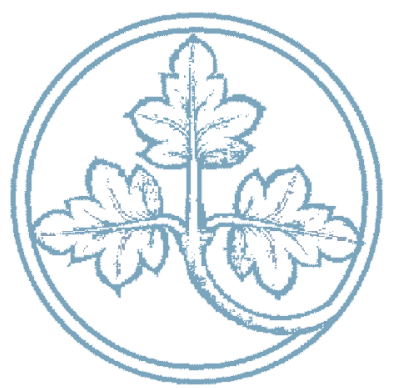

Increasing Workload in a Stochastic Environment

Philipp Weinschenk

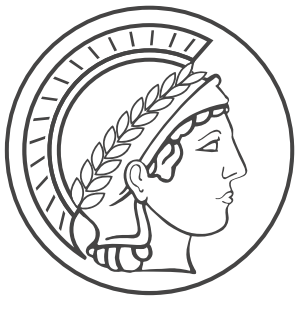




\title{
Increasing Workload in a Stochastic Environment
}

\author{
Philipp Weinschenk
}

November 2010

revised version April 2012 


\title{
INCREASING WORKLOAD IN A STOCHASTIC ENVIRONMENT
}

\author{
PhiLIPP WeInsCHENK*
}

April 25, 2012

\begin{abstract}
We show that a steeply increasing workload before a deadline is compatible with time-consistent preferences. The key departure from the literature is that we consider a stochastic environment where success of effort is not guaranteed.
\end{abstract}

JEL Classification: D91, J22, D81, D11.

Keywords: Increasing Workload, Deadline, Stochasticity.

\section{INTRODUCTION}

Life is full of tasks which have to be completed by a prespecified date. People sometimes delay the completion of such tasks. ${ }^{1}$ Their workload is steeply increasing before the deadline. The literature explains this phenomenon by use of time-inconsistent, present-biased preferences (O'Donoghue and Rabin, 1999, 2001, 2007; Akerlof, 1991; Brocas and Carrillo, 2001). In contrast, typical models with time consistency predict that a person distributes her effort equally across time (O'Donoghue and Rabin, 2007). Because of discounting, a time-consistent person may optimally choose a slightly increasing workload (Fischer, 2001). However, "quantitatively, the fully rational model appears to require an extremely high rate of time preference or elasticity of intertemporal substitution to generate serious procrastination" (Fischer, 2001, p. 249). That is, a steeply increasing workload is seen as incompatible with the time consistency assumption.

We show that in a stochastic environment, where success of effort is not guaranteed, a time-consistent person may optimally choose a steeply increasing workload. Therefore, we provide - to the best of our knowledgethe first explanation why a steeply increasing workload can be fully rational.

*Max Planck Institute for Research on Collective Goods, Kurt-Schumacher-Str. 10, 53113 Bonn, Germany, weinschenk@coll.mpg.de. I thank an anonymous referee, Christoph Engel, Martin Hellwig, Fabian Herweg, Oliver Himmler, Aniol Llorente-Saguer, Daniel Müller, and Dan Silverman, as well as seminar participants at the Max Planck Institute and at the EEA Conference 2010 in Glasgow for helpful comments and suggestions.

${ }^{1}$ See Ellis and Knaus (1977), Solomon and Rothblum (1984), McCown et al. (1987), and Ariely and Wertenbroch (2002). 


\section{THE MODEL}

The person has to solve some task within $T \geq 2$ periods. In every period $t \in\{1, \ldots, T\}$, she chooses how much effort $p_{t}$ she wants to invest. We measure effort in units of success, so $p_{t} \in[0,1]$. The effort costs in period $t$ are $c=f\left(p_{t}\right)$. We suppose that zero effort is costless, $f(0)=0$, and that effort costs are increasing and convex: $f^{\prime}\left(p_{t}\right)>0$ for all $p_{t}>0$ and $f^{\prime \prime}\left(p_{t}\right)>0$ for all $p_{t}$. To guarantee inner solutions we suppose that $f^{\prime}(0)=0$. We denote the expected effort costs of solving the task under the optimal strategy, given that the task is not solved at the beginning of period $t$, by $E_{t}[C]$.

\section{ANALYSIS}

When the task is not solved at the beginning of period $T$, the person has to make sure that the task is solved in $T$ and therefore chooses effort $p_{T}^{*}=1$. In period $t<T$, and when the task is not yet solved, the person minimizes the expected efforts cost of a solution

$$
E_{t}[C]=f\left(p_{t}^{*}\right)+\left(1-p_{t}^{*}\right) E_{t+1}[C]
$$

over $p_{t}$. The first-order condition is

$$
f^{\prime}\left(p_{t}^{*}\right)-E_{t+1}[C]=0 .
$$

With $p_{T}^{*}=1,(1)$ and (2) determine the optimal sequence of efforts $\left(p_{1}^{*}, \ldots, p_{t}^{*}\right.$, $\left.\ldots, p_{T}^{*}\right)$ which the person chooses when the task is not yet solved. When the task is solved, it is optimal to choose zero effort.

From (2) we see that the person invests more, the higher are the expected effort costs of solving the task under the optimal strategy:

$$
\frac{d p_{t}^{*}}{d E_{t+1}[C]}=\frac{1}{f^{\prime \prime}\left(p_{t}^{*}\right)}>0
$$

We now show that $E_{t}[C]<E_{t+1}[C] \forall t \leq T-1$. We start with $t=T-1$. Rewrite (1) as

$$
E_{T-1}[C]=E_{T}[C]+p_{T-1}\left(\frac{f\left(p_{T-1}\right)}{p_{T-1}}-E_{T}[C]\right) .
$$

The person can choose a small $p_{T-1}$. Then

$$
\left(\frac{f\left(p_{T-1}\right)}{p_{T-1}}-E_{T}[C]\right)<0
$$

because $f\left(p_{T-1}\right) / p_{T-1}$ is then small, ${ }^{2}$ while $E_{T}[C]=f(1)$. Note that the person need not choose a small $p_{T-1}$; but because she minimizes $E_{T-1}[C]$,

\footnotetext{
${ }^{2}$ More precisely, due to convexity of $f, 0 \leq \frac{f(p)}{p}<f^{\prime}(p)$ and hence $\lim _{p \rightarrow 0} \frac{f(p)}{p}=0$.
} 
(4) and (5) imply that $E_{T-1}[C]<E_{T}[C]$ must hold. The same steps can be repeated for period $t=T-2$ and so on.

We claim that the effort levels which the person optimally chooses are increasing over time:

$$
0<p_{t}^{*}<p_{t+1}^{*}, \forall t \leq T-1 .
$$

First, $E_{T-1}[C]<E_{T}[C], E_{T}[C]=f(1)$, and (4) imply that $p_{T-1}^{*}<p_{T}^{*}=1$. Second, the finding that $E_{t}[C]<E_{t+1}[C]$ for all $t \leq T-1$ implies, together with (3), that $p_{t}^{*}<p_{t+1}^{*} \forall t \leq T-2$. Finally, $p_{t}=0$ would imply, see (1), $E_{t}[C]=E_{t+1}[C]$, which cannot hold.

The assumption that $f^{\prime}(p)>0$ for $p>0$ and (6) imply that effort costs are increasing over time as well:

$$
f\left(p_{t}^{*}\right)<f\left(p_{t+1}^{*}\right), \forall t \leq T-1 .
$$

The next proposition summarizes.

P R O P O S I T I O N 1: Given that the task is not yet solved, the workload, $f\left(p_{t}^{*}\right)$, is increasing over time.

The intuition is as follows. Shortly before the deadline, solving the task becomes urgent and the person consequently invests a lot of effort. In early periods, the person could also decide to invest a lot of effort and therefore likely solve the task then already. However, this is not optimal. Rather, the person optimally invests little effort to solve the task possibly for low effort costs. ${ }^{3}$ Therefore, the option of solving the task in later periods provides incentives for the person to try to solve the task with little effort in early periods.

As a concrete example, suppose that a schoolchild has to complete a homework within two days. If the work is not completed on day 1 , the child has to invest a lot of effort on day 2 to complete the work for sure. For example, the child may do its homework independently, which causes high effort costs. On day 1, the child optimally invests less effort to minimize the expected effort costs of solving the task. For example, the child may browse the web for a solution, which causes low effort costs, but is not sure to succeed.

\section{PARAMETRIC EXAMPLE}

Suppose

$$
f(p)=\alpha p^{\gamma}
$$

\footnotetext{
${ }^{3}$ Notice that for low levels of effort the likelihood of success is large relative to the effort costs: $p / f(p)$ is decreasing in $p$ due to $f(0)=0$ and $f^{\prime \prime}>0$. Loosely speaking, investing little effort gives the person a lot of "bang for the buck".
} 
with $\alpha>0, \gamma>1$, and $p \in[0,1]$. Since the expected costs of a solution $E_{t}[C]$ are also linear in $\alpha$, we can normalize $\alpha=1$.

Figure 1 shows for selected values of $\gamma$ how the optimal effort, the effort costs, and the expected costs of a solution evolve over a timespan of 10 periods. ${ }^{4}$ The diagrams illustrate that a steeply increasing workload can be optimal. It is hard to qualify what "steeply" means. Nevertheless, we think that, for example, the quadrupling of the effort costs $f\left(p_{t}^{*}\right)$ from the penultimate to the last period in the quadratic cost specification $(\gamma=2)$ can be seen as a steep increase.
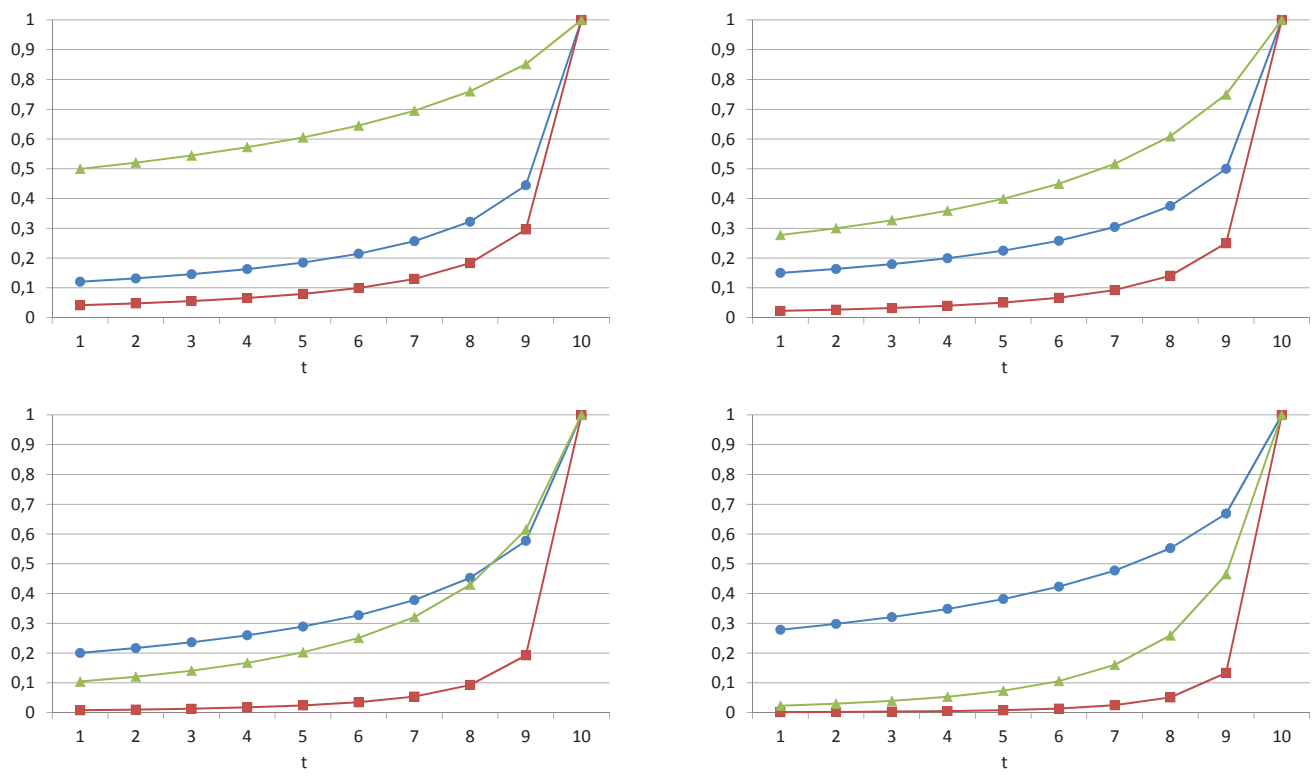

F I G U R E 1: Examples with $\gamma=1.5$ (top left), $\gamma=2$ (top right), $\gamma=$ 3 (bottom left), and $\gamma=5$ (bottom right); $p_{t}^{*}$ (blue circles), $f\left(p_{t}^{*}\right)$ (red squares), and $E_{t}[C]$ (green triangles).

\section{CONCLUSION AND EXTENSIONS}

We offered a simple model where the success of effort is stochastic and showed that a person with time-consistent preferences may optimally choose a steeply increasing workload before a deadline. We next show that this result also holds when we consider (i) discounting and (ii) a setting where solving the task is no longer mandatory but instead rewarded.

\footnotetext{
${ }^{4}$ When a shorter horizon, $T<10$, is considered, one has to cut off the first $10-T$ periods of the diagrams.
} 


\subsection{DISCOUNTING}

What happens when future costs are discounted with factor $\delta \in(0,1)$ ? We consider the simple case where $f(p)=p^{\gamma}$ and $T=2$. In $t=2$, the person chooses $p_{2}^{*}=1$. In $t=1$, she minimizes, cf. (1),

$$
p_{1}^{\gamma}+\delta\left(1-p_{1}\right) 1
$$

over $p_{1}$. This yields

$$
p_{1}^{*}=\left(\frac{\delta}{\gamma}\right)^{\frac{1}{\gamma-1}} .
$$

Observe that discounting has a negative impact on $p_{1}^{*}$, which makes the workload even more sharply increasing over time. Because $p_{1}^{*}$ is continuous in $\delta$, discount factors close to 1 lead to results which are quantitatively very similar to the ones without discounting.

\subsection{REWARD}

Some real-world situations may be better described by assuming that a task does not have to be solved for sure, but rather that solving it is rewarded (or equivalently, that failure is punished). Let the reward for solving the task within the deadline be $R>0$. We consider the case where $T=2$. In $t=2$, the person is no longer forced to choose $p_{2}=1$. She maximizes the expected reward minus her effort costs:

$$
\max _{p_{2}} p_{2} R-f\left(p_{2}\right)
$$

If $R \geq f^{\prime}(1)$ the person chooses to solve the task for sure: $p_{2}^{*}=1$. Otherwise, $p_{2}^{*}$ solves

$$
f^{\prime}\left(p_{2}^{*}\right)=R
$$

In $t=1$, she maximizes the expected reward minus her effort costs and also takes into account that by solving the task now she foregoes the continuation payoff of eventually solving the task in period 2 :

$$
\max _{p_{1}} p_{1} R-f\left(p_{1}\right)-p_{1}\left(p_{2}^{*} R-f\left(p_{2}^{*}\right)\right)
$$

We now prove that $p_{1}^{*}<p_{2}^{*}$. Suppose, contrary to our claim, that $p_{1}^{*}>p_{2}^{*}$. Then $p_{2}^{*}$ is smaller than 1 and solves (12). The first-order condition of (13) is

$$
f^{\prime}\left(p_{1}\right)=R-\left(p_{2}^{*} R-f\left(p_{2}^{*}\right)\right) .
$$

Comparing (12) and (14) clarifies that $p_{1}^{*}$ cannot exceed $p_{2}^{*}$ because the continuation payoff is positive (due to $0=f^{\prime}(0)<R$ ). The same line of arguments implies that $p_{1}^{*}=p_{2}^{*}<1$ cannot hold. It remains to show that 
whenever $p_{2}^{*}=1$, we have $p_{1}^{*}<1$. If $p_{2}^{*}=1$, the continuation payoff of reaching period 2 , when the task is not solved yet solved, is $R-f(1)$. Using this result, we see from (14) that $p_{1}^{*}=1$ requires

$$
f^{\prime}(1) \leq f(1)
$$

which cannot hold, given the assumptions made on $f$. Because effort costs are increasing, $p_{1}^{*}<p_{2}^{*}$ implies that the workload is increasing over time: $f\left(p_{1}^{*}\right)<f\left(p_{2}^{*}\right)$.

\section{APPENDIX: NUMERICAL RESULTS}

Here are the numerical data of the $T=10$ example for different values of $\gamma$. The calculations were made with the software Microsoft Excel. $E_{0}\left[f\left(p_{t}^{*}\right)\right]$ denotes the unconditional expected effort costs of period $t$, from the perspective of period 0 . The tables reveal that also the unconditional expected effort costs (which can be interpreted as the expected workloads) are increasing over time. Simulations show that this result holds more generally.

\begin{tabular}{ccccc}
\hline \hline$t$ & $p_{t}$ & $f\left(p_{t}\right)$ & $E_{0}\left[f\left(p_{t}^{*}\right)\right]$ & $E_{t}[C]$ \\
\hline 1 & 0.120588060 & 0.041875158 & 0.041875158 & 0.499949295 \\
2 & 0.131937950 & 0.047924170 & 0.042145087 & 0.520886874 \\
3 & 0.145757348 & 0.055647504 & 0.042480421 & 0.544848959 \\
4 & 0.162985877 & 0.065799858 & 0.042909093 & 0.572672711 \\
5 & 0.185129507 & 0.079655078 & 0.043478108 & 0.605572640 \\
6 & 0.214783103 & 0.099540580 & 0.044273711 & 0.645400179 \\
7 & 0.256896533 & 0.130207909 & 0.045475005 & 0.695170469 \\
8 & 0.322511812 & 0.183154856 & 0.047533864 & 0.760274424 \\
9 & 0.444444444 & 0.296296296 & 0.052096990 & 0.851851852 \\
10 & 1 & 1 & 0.097681856 & 1 \\
\hline \multicolumn{5}{c}{} \\
\hline
\end{tabular}

TA B L E 1: $\gamma=1.5$.

\begin{tabular}{ccccc}
\hline \hline$t$ & $p_{t}$ & $f\left(p_{t}\right)$ & $E_{0}\left[f\left(p_{t}^{*}\right)\right]$ & $E_{t}[C]$ \\
\hline 1 & 0.150178593 & 0.022553610 & 0.022553610 & 0.277803576 \\
2 & 0.163553460 & 0.026749734 & 0.022732497 & 0.300357185 \\
3 & 0.179699396 & 0.032291873 & 0.022954038 & 0.327106919 \\
4 & 0.199624333 & 0.039849875 & 0.023236240 & 0.359398792 \\
5 & 0.224918499 & 0.050588331 & 0.023609300 & 0.399248667 \\
6 & 0.258270264 & 0.066703529 & 0.024128424 & 0.449836998 \\
7 & 0.304687500 & 0.092834473 & 0.024907785 & 0.516540527 \\
8 & 0.375 & 0.140625 & 0.026234235 & 0.609375 \\
9 & 0.5 & 0.25 & 0.029149150 & 0.75 \\
10 & 1 & 1 & 0.058298299 & 1 \\
\hline
\end{tabular}

TA B L E 2: $\gamma=2$. 


\begin{tabular}{ccccc}
\hline \hline$t$ & $p_{t}$ & $f\left(p_{t}\right)$ & $E_{0}\left[f\left(p_{t}^{*}\right)\right]$ & $E_{t}[C]$ \\
\hline 1 & 0.200609649 & 0.008073381 & 0.008073381 & 0.104585932 \\
2 & 0.216904170 & 0.010204781 & 0.008157604 & 0.120732694 \\
3 & 0.236316697 & 0.013197243 & 0.008261464 & 0.141142257 \\
4 & 0.259903612 & 0.017556460 & 0.008393132 & 0.167536743 \\
5 & 0.289293373 & 0.024211152 & 0.008566252 & 0.202649663 \\
6 & 0.327163966 & 0.035018408 & 0.008805665 & 0.251071967 \\
7 & 0.378338133 & 0.054155223 & 0.009162529 & 0.321108782 \\
8 & 0.452806000 & 0.092840296 & 0.009764854 & 0.429419228 \\
9 & 0.577350269 & 0.192450090 & 0.011076146 & 0.615099821 \\
10 & 1 & 1 & 0.024324905 & 1 \\
\hline \multicolumn{5}{c}{}
\end{tabular}

TA B L E 3: $\gamma=3$.

\begin{tabular}{ccccc}
\hline \hline$t$ & $p_{t}$ & $f\left(p_{t}\right)$ & $E_{0}\left[f\left(p_{t}^{*}\right)\right]$ & $E_{t}[C]$ \\
\hline 1 & 0.278513901 & 0.001675847 & 0.001675847 & 0.023382131 \\
2 & 0.298148091 & 0.002355918 & 0.001699762 & 0.030085519 \\
3 & 0.321121843 & 0.003414674 & 0.001729110 & 0.039509191 \\
4 & 0.348458374 & 0.005137532 & 0.001766118 & 0.053167886 \\
5 & 0.381688940 & 0.008101172 & 0.001814493 & 0.073718014 \\
6 & 0.423246156 & 0.013582043 & 0.001880960 & 0.106122704 \\
7 & 0.477334268 & 0.024780671 & 0.001979329 & 0.160450877 \\
8 & 0.552233245 & 0.051358548 & 0.002144084 & 0.259573562 \\
9 & 0.668740305 & 0.133748061 & 0.002500163 & 0.465007756 \\
10 & 1 & 1 & 0.006192264 & 1 \\
\hline \multicolumn{5}{c}{} \\
\hline
\end{tabular}

TA B L E $4: \gamma=5$. 


\section{LITERATURE}

Akerlof, George A. (1991). Procrastination and Obedience. American Economic Review Papers 85 Proceedings 81, 1-19.

Ariely, Dan and Klaus Wertenbroch (2002). Procrastination, Deadlines, and Performance: Self-Control by Precommitment. Psychological Science 13, 219-224.

Brocas, Isabelle and Juan D. Carrillo (2001). Rush and Procrastination Under Hyperbolic Discounting and Interdependent Activities. Journal of Risk and Uncertainty 22, 141-164.

Ellis, Albert and William J. Knaus (1977). Overcoming Procrastination. Institute for Rational Living, New York.

Fischer, Carolyn (2001). Read this Paper Later: Procrastination with Time-Consistent Preferences. Journal of Economic Behavior $\& 3$ Organization 46, 249-269.

McCown, William, Thomas Petzel, and Patricia Rupert (1987). An Experimental Study of some Hypothesized Behaviors and Personality Variables of College Student Procrastinators. Personality and Individual Differences 8, 781-786.

O'Donoghue, Ted and Matthew Rabin (1999). Doing It Now or Later. American Economic Review 89, 103-124.

O'Donoghue, Ted and Matthew Rabin (2001). Choice and Procrastination. Quarterly Journal of Economics 116, 121-160.

O'Donoghue, Ted and Matthew Rabin (2007). Incentives and Self Control. In Richard Blundell, Whitney Newey, and Torsten Persson, eds., Advances in Economics and Econometrics, Volume 2: Theory and Applications (Ninth World Congress), Cambridge University Press, 215-245.

Solomon, Laura J. and Esther D. Rothblum (1984). Academic Procrastination: Frequency and Cognitive-Behavioral Correlates. Journal of Counseling Psychology 31, 503-509. 